\title{
O TRATAMENTO DA VIOLÊNCIA URBANA NAS REVISTAS NACIONAIS
}

\section{THE TREATMENT OF URBAN VIOLENCE IN NATIONAL MAGAZINES}

\author{
Caroline Leal ${ }^{1}$ \\ Carlos Alberto de Souza ${ }^{2}$
}

\begin{abstract}
RESUMO
O objetivo deste artigo é analisar o tratamento das revistas Veja, Isto é, Época e Carta Capital sobre o tema da violência urbana. As publicações, consolidadas no mercado editorial, utilizam-se de diversas estratégias jornalísticas para atingir o público, uma das quais é potencializar em suas capas e reportagens as tragédias vivida pela nação brasileira - por exemplo, crime organizado, tráfico de drogas e assassinatos. A investigação permitiu apontar, também, as contribuições que os periódicos oferecem à solução de tais problemas, se apontam os caminhos para que a violência no Brasil possa ser resolvida. As informações foram interpretadas com o uso das técnicas da Análise de Conteúdo, por meio de um cruzamento entre as abordagens qualitativa e quantitativa. Também foi utilizado o método comparativo e a pesquisa bibliográfica.

Palavras-chave: Revistas. Violência. Sensacionalismo.
\end{abstract}

\begin{abstract}
The aim of this article is to analyze the treatment of the Brazilian magazines Veja, Isto é, Época and Carta Capital about urban violence. The publications, consolidated in the market, make use of several journalistic strategies to reach the public, one of which is to improve their covers and report the tragedies experienced by the Brazilian nation - for instance, organized crime, drug trafficking and murder. The investigation has also allowed to point out the contributions of the magazines to the solution of such problems, how to end the issue of violence in Brazil. The data were interpreted using the techniques of content analysis, through a cross between qualitative and quantitative methods. The comparative method and bibliography research was also used.
\end{abstract}

Keywords: Magazines. Violence. Sensationalism.

1 Graduada em Jornalismo pela Universidade do Vale do Itajaí e integrante voluntária do Laboratório de Mídia, Cultura e Estética da Univali. E-mail: carolineleal@gmail.com.

2 Doutor em Ciências Humanas e Mestre em Comunicação Social pela UFRGS. Professor do Curso de Jornalismo da UEPG, coordenador e orientador da pesquisa. E-mail: carlossouza2013@hotmail.com. 


\section{Violência como estratégia midiática}

A questão da violência nos meios de comunicação tem preocupado a sociedade brasileira. Os atos violentos praticados em nosso cotidiano por bandidos, traficantes, sequestradores, ou mesmo por pessoas comuns, até devem ser mostrados, mas o problema é a forma de exploração desse tema que tem por finalidade atrair os leitores e aumentar a fatia de lucro no mercado competitivo da comunicação. Como observa Wainberg (2005, p. 12), "a riqueza visual da violência serve com estimulante" para o público. As fotos, por exemplo, motivam os leitores a abrir uma revista. Fotos e manchetes precisam ser bem trabalhadas e os editores sabem que isso pesa na hora da venda, no processo de comercialização da revista.

A violência tem sido tema prioritário na mídia. Ver a desgraça alheia parece ajudar as pessoas a suportar a própria realidade. Muitas delas acabam se consolando com a situação e dramas que vivem, quando tomam conhecimento da angústia vivida por outras pessoas e famílias.

Para apresentar como as revistas nacionais abordam a temática e as contribuições que trazem ao debate, resolveu-se abordar as quatro principais revistas brasileiras - Veja, Isto é, Época e Carta Capital. Elas trazem à tona o tema da violência urbana nas principais cidades brasileiras estabelecendo, muitas vezes, a "imagem" de que o Brasil vive um quadro de descontrole social.

O poder dessas revistas no imaginário coletivo é grande por se configurarem como produções sérias e éticas e, também, pelo poder de difusão de suas mensagens. O desenvolvimento do trabalho se baseou em pesquisa bibliográfica e em Análise de Conteúdo (AC). Bardin (2000) defende o uso desse método e de suas técnicas, quantitativa e qualitativa, no estudo das mensagens e textos do campo da comunicação. Optou-se, ainda, pela pesquisa bibliográfica e comparativa. $\mathrm{O}$ assunto continua sendo atual e diz respeito a todos.

Para o desenvolvimento das análises, foram selecionados 12 exemplares de cada publicação e também buscou-se explorar o tratamento dado pelos periódicos a casos marcantes que tiveram muita repercussão no meio social. A primeira parte da pesquisa foi realizada em 2007, porém jamais foi publicada. Atualmente, estamos organizando uma nova etapa de investigação, com a finalidade de verificar como esse tema continua sendo retratado pelos periódicos. Esta nova pesquisa deverá ser concluída em 2014 e, novamente, abrangerá as quatro revistas nacionais. O objetivo é verificar como, depois de oito anos, a mídia continua explorando a questão. Retorna-se, nesta análise específica, ao caso do menino João Hélio, de grande repercussão na mídia, para um aprofundamento da análise qualitativa. A atenção foi dada às capas, editoriais e reportagens sobre a violência urbana.

\section{A título de introdução}

O que é violência? Michaud (1989) explica que o termo tem origem no latim violentia, significando violência, caráter violento ou bravio, força. $\mathrm{O}$ verbo violare significa tratar com violência, profanar, transgredir. Acrescenta:

Para onde quer que nos voltemos, encontramos no âmago da noção de violência a ideia de uma força, de uma potência natural cujo exercício contra alguma coisa ou contra alguém torna o caráter violento. [...] Ela (a força) se torna violência quando passa da medida ou perturba a ordem (MICHAUD, 1989, p.8).

Para o autor (p. 16), existe violência quando “[...] um ou vários atores agem de maneira direta ou indireta, maciça ou esparsa, causando danos a uma ou várias pessoas em graus variáveis, seja em sua integridade física, seja em sua integridade moral, em suas posses, ou em suas participações simbólicas e culturais".

Arendt (2001, p. 9) observa que a violência e sua glorificação explicam-se pela "severa frustração da faculdade de agir no mundo contemporâneo, que tem suas raízes na burocratização da vida pública, na vulnerabilidade dos grandes sistemas e na monopolização do poder, que seca as autênticas fontes criativas".

Odália (1991), por sua vez, observa que ela é uma forma de privar ou subjugar pela força. Por isso, 
há necessidade de estabelecer, por meio de leis, tradições e costumes, sanções e punições para o controle da violência social. Dias (2003, p. 105) explica que:

A palavra [...] possui diferentes acepções para pessoas diferentes vivendo em sociedades diferentes, e mesmo para pessoas que vivem no interior de uma mesma sociedade. Um comportamento considerado violento e repreensível por um grupo, pode ser julgado necessário e legítimo por um outro.

Maffesoli (1987) vê a violência sob o aspecto negativo, mas a considera como elemento inerente à sociedade. Para ele, o termo "luta", por exemplo, é fundamento de qualquer relação social. Ele concede à violência o papel de "estruturante coletivo" responsável pela promoção do dinamismo das sociedades.

A violência faz parte da história do homem e caminhou lado a lado com a civilização. E chega, observa Odália (1991), aos dias de hoje nas mais diversas formas: física, racial, sexual, religiosa, política e econômica.

Há um universo bastante extenso em que o fenômeno se expressa. Vivencia-se, por meio dos veículos de comunicação, muitas cenas de violência: chacina, guerra, tortura, assassinato, fome, preconceito.

As formas de violência, tipificadas como violação da lei penal, a exemplo dos assassinatos, sequestros, roubos e outros tipos de crime contra a pessoa ou contra o patrimônio, formam um conjunto que se convencionou chamar de violência urbana, porque se manifesta principalmente no espaço das grandes cidades.

A violência urbana não compreende apenas os crimes, mas todo o efeito que provoca sobre as pessoas e as regras de convívio nas cidades modernas. Certamente, o tráfico de drogas, talvez a ramificação mais visível do crime organizado, acentua esse quadro, sobretudo nas grandes e problemáticas periferias. A violência urbana abarca também a "violência branca”, que pode ser resumida por uma série de pequenos crimes praticados diária e subterraneamente, por uma sociedade injusta e discriminatória, contra o cidadão (PIRES, 1994, p.14).

A violência não deve ser associada apenas à miséria material e à desigualdade - há outros fatores que ativam o fenômeno. Mas, certamente, o distanciamento acentuado entre as classes sociais e os fatores econômicos, que excluem parcela da população do acesso aos seus direitos básicos, favorecem o seu florescimento e a "desordem social".

As raízes da violência estão associadas fundamentalmente à estrutura de poder vigente em uma dada sociedade. O funcionamento dessa estrutura de dominação envolve um processo complexo, que se centraliza no desequilíbrio social entre os fortes e os fracos. O jogo político de forças produz e reproduz a ordem das ruas, becos e praças da cidade. Muitos governos privilegiaram a autoridade em detrimento do consenso; concentraram o poder político em torno de poucos, deixando de lado as instituições representativas, que passaram a ter caráter meramente cerimonial; restringiram a liberdade; suprimiram as oposições ou as coagiram à simulação.

O Brasil apresenta uma violência histórica, cujas raízes não derivam necessariamente do que denominamos hoje de globalização ou crescimento populacional, suas causas são também históricas, derivadas da grande concentração de renda e de terras e da impunidade. O problema é que a essas causas históricas somam-se as novas, o que torna o fenômeno ainda mais complexo e de difícil dimensionamento. A violência contemporânea, conforme afirma Michaud (1989, p. 16), muda de fisionomia porque é o produto de sociedades que "mudaram a administração de todos os aspectos da vida social, a tecnologia e os meios de comunicação de massa (mídia)".

\section{Mídia e violência}

A violência urbana, entendida como criminalidade nas grandes cidades, está diariamente nos jornais. "[...] porque esse intenso e incansável interesse pela violência e suas manifestações [...] por parte dos meios de comunicação de massas?", pergunta Pires (1994, p.276). A resposta é simples: porque há interesse público a respeito do assunto, porque todos querem saber e se proteger da violência. A mídia parece necessitar desses acontecimentos. "A violência, com a carga de ruptura que ela veicula, é por princípio um 'alimento' privilegiado para a mídia, com vantagem para as violências espetaculares, sangrentas ou 
atrozes [...]". (MICHAUD, 1989, p.49). A violência urbana está nas ruas e nos jornais diários, infesta a programação televisiva e nossas preocupações cotidianas. No entanto, cada um é atingido de forma diferente por esse volume de informações. Pinheiro (1983, p. 251) observa que "a classe social a que pertencemos, o local onde moramos, o jornal que lemos, o programa a que assistimos, bem como a imagem que estes nos dão de nossa classe social e do local onde moramos, constituem e compõem o modo como vivenciamos e pensamos essa violência".

Vários elementos se fazem presentes no cenário da violência: as vítimas, a atuação da polícia e do governo, o agressor, a família, o círculo social das vítimas e criminosos e a população que assiste perplexa aos acontecimentos do cotidiano. Como fenômeno complexo, a violência pode ser analisada por diversos ângulos, não necessariamente contraditórios entre si, podendo ser destacado ou privilegiado algum aspecto da análise, sem esgotar o problema.

O objeto de análise desta pesquisa são as quatro maiores revistas semanais de informação do país - Veja, Isto é, Carta Capital e Época. Como elas abordam e divulgam a violência urbana. Com uma tiragem superior, na época (2007) um milhão de exemplares, a Veja (Editora Abril), criada em 1968 pelos jornalistas Victor Civita e Mino Carta, é a revista de maior circulação no Brasil e a quarta maior semanal do mundo. A revista Isto é (Editora Três), fundada em 1976, também foi uma criação do jornalista italiano Mino Carta, que lançou ainda a revista Carta Capital. Sua tiragem oscila entre 420 e 450 mil exemplares semanais. É uma revista que aborda assuntos variados e de forma leve, desde temas sobre a saúde feminina até espiritismo, por exemplo.

A Carta Capital foi pensada como uma alternativa à Veja e à Isto é. Como não foi possível superá-las, em termos de fatia do mercado, assumiu uma postura de análise crítica. Sua tiragem média é de 75 mil exemplares.

A Época surgiu em 25 de maio de 1998 (Editora Globo) e tem hoje uma circulação média estimada em aproximadamente 450 mil exemplares semanais. Atinge as classes A e B. A filosofia da revista é ser informativa e isenta. Apresenta os fatos e deixa a cargo do leitor interpretá-los.

\section{O tratamento da violência}

A pesquisa sobre o tema da violência faz parte de um trabalho mais amplo, como já se observou anteriormente, que procura mapear o tratamento dispensado pelos meios de comunicação à violência urbana. Para se ter uma ideia de como isso acontece, escolheu-se aleatoriamente exemplares (um total de 12) das 4 revistas nacionais no período de julho a setembro de 2007, totalizando uma amostragem de 48 exemplares. Nesta primeira etapa da pesquisa, verificou-se que cerca de $50 \%$ das publicações trataram, de alguma forma, do assunto, apresentado em 34 reportagens, quatro capas e um editorial. Dos 12 exemplares analisados da revista Época, oito deles $(66,6 \%)$, abordaram a questão da violência. $\mathrm{Na}$ Carta Capital, o assunto apareceu em sete edições (58,3\%). Na Veja, a violência foi tema em cinco publicações $(41,6 \%)$, seguida pela Isto é, com quatro exemplares $(33,3 \%)$.

Os números, de certa forma, surpreenderam. Esperava-se um tratamento mais intensivo por parte das revistas a respeito do tema. Contudo, o país - à época -, vivia uma nova crise política (Mensalão) e os Jogos Pan-Americanos, assuntos que despertavam a atenção da mídia. A revista Carta Capital trata da violência utilizando uma linguagem mais crítica do que a de suas concorrentes. Com quatorze reportagens abordavam o tema, foi a que dedicou maior espaço à temática e a que mais expôs o assunto na capa (três vezes), com as seguintes chamadas: "O plano nacional de segurança" e "De mocinho a bandido um mergulho nos mecanismos que levam policiais a matar, torturar, extorquir e roubar", que se referiam a três matérias: "Armas e Flores", "Sobre Polícia e Politicagem" e "Criminosos fardados".

O assunto, Plano de Segurança, p. 36 a 41, tratava dos investimentos e ações propostas no plano de segurança nacional que pretendia, além de coibir a violência urbana, reprimir a má conduta de policias. O texto, fotos e infográficos apresentavam natureza apenas informativa. Não há apelo nas imagens, nem no conteúdo. Isso se repete na segunda reportagem, editada nas páginas 42 a 47 . Nela, pesquisadores apresentam dados e estatísticas, e dão diversos exemplos de casos de má conduta policial, propondo 
uma discussão acerca da corrupção e impunidade desses profissionais.

A Carta Capital publicou ainda uma nota, na sessão A semana, intitulada "Dinheiro não basta", apontando que os investimentos estaduais em segurança pública não têm auxiliado na diminuição dos índices de criminalidade nas cidades. A matéria sobre o uso das Forças Armadas no combate à violência; a violência nas escolas públicas do país; e a prisão de policias no rio - que ao invés de trabalhar na repressão à violência, estão envolvidos com o tráfico -, foram outros assuntos priorizados pela publicação.

Chamamos atenção para as entrevistas: uma sobre o controle da tevê mundial, para coibir a exibição da violência nas telas; e outra sobre um videoclipe lançado no YouTube, com a música "Classe Média", de autoria do entrevistado Max Gonzaga e Banda Marginal, que fez uma forte crítica ao papel da classe média em relação à violência: "Sou classe média, Papagaio de todo telejornal. Eu acredito, na imparcialidade da revista semanal. Mas eu 'tô nem aí', se o traficante é quem manda na favela, eu não 'tô nem aí', se morre gente ou tem enchente em Itaquera, eu quero é que se exploda a periferia toda".

Poucas fotos, pouco sensacionalismo. Foi a única publicação que apresentou uma série de reportagens discutindo o problema da segurança no país e mostrando pontos de vista de especialistas, que indicaram sugestões e ideias que podem ser utilizadas para diminuir a violência urbana do Brasil.

A revista Época também apresentou um número considerável de reportagens (dez), reservando maior número de páginas (51) ao assunto, se comparado às outras revistas. $\mathrm{Na}$ Carta Capital, o tema ocupou 36 páginas, seguida pelas revistas Isto é e Veja, que utilizaram 21 e 17, respectivamente.

A Época apresentou a violência de forma diversificada e sob ângulos diferentes. O combate ao tráfico, no Complexo do Alemão, ganhou "tom" humanitário: "Mais que uma troca de tiros" (p.118120), edição de 9 de julho. O texto expõe os motivos para as invasões policiais lá ocorridas e as medidas que estão sendo tomadas no combate ao tráfico, “Apenas o confronto com o tráfico não basta. É preciso que o Estado entre, permaneça e seja aceito, para que o país acredite que é possível vencer a violência" (p.120). Uma matéria que cumpre bem o papel que deveria fazer a mídia.

A revista tratou, ainda, de temas como: os investimentos em segurança pública; a queda da criminalidade, e se ela pode impulsionar a economia e o crescimento; o perfil da nova geração de traficantes; e as cidades brasileiras com maior índice de violência. As reportagens foram escritas de forma narrativo-informativa, sem muita literalidade e sem recorrer ao sensacionalismo.

Dois assuntos tiveram destaque na revista Época: a repercussão do filme Tropa de Elite e o combate ao crime no Rio de Janeiro. Ambos ganharam capas. Na edição n. 476, de julho, a manchete "Um ataque inovador - por que o cerco aos traficantes no Rio é um marco no combate ao crime no Brasil" chamava o leitor para a matéria de 16 páginas, intitulada: "Os novos rumos da guerra contra o crime". De toda a análise, a melhor matéria - pelo ponto de vista que considera que os meios de comunicação ao invés de expor os acontecimentos de forma sensacionalista, devem se preocupar em mostrar soluções para as questões da violência.

Depois de explicar em três páginas o que estava acontecendo no Complexo do Alemão e o porquê das invasões, a revista pareceu cumprir o seu papel. As páginas seguintes apresentam oito sugestões, elaboradas com a ajuda de especialistas, para conter a violência e melhorar a segurança nas cidades brasileiras. "É nossa contribuição para uma das questões mais urgentes que o país precisa resolver” (p. 2). Um exemplo que deveria ser seguido por todos os veículos de comunicação.

A outra edição que destacou a violência na capa, anunciava em manchete: "Tropa de Elite" por que este é o filme mais quente daquele ano - e nas páginas internas, na matéria "Polícia, drogas, ação" (p.93-99), discutia-se não só a grande popularidade nas telas, mas a problemática da criminalidade envolvida no enredo da obra, contendo fotos de cenas fortes do filme, mostrando corpos e armas. Além disso, o modo de diagramação da matéria serviu de forte apelo para a leitura.

Das quatro revistas analisadas, a que menos trouxe reportagens sobre a violência foi a Veja. Coincidência ou não, foi a que mais esbanjou editoriais, matérias e especiais sobre política, fato já 
esperado diante da linha da revista, que prioriza acontecimentos atuais que tenham grande apelo, como o escândalo político do Mensalão, ocorrido no período de análise. Essa postura não é exclusividade da Veja. As demais revistas, jornais e a televisão reproduzem essa sensação de crise que quase nunca dá em nada. Quando os acontecimentos começam a se complicar, são disfarçados: comemora-se uma cassação isolada, ou "cria-se" uma nova denúncia.

Nesse período, uma reportagem expressiva foi publicada na Veja, edição n. 30, de agosto: "Colômbia - depois de domar o crime, o país renasce para a modernidade" (p.106-113). Apesar de se concentrar na "volta por cima" do país vizinho, o periódico tratou o assunto como um exemplo a ser seguido por outros países e observou que medidas poderiam ser "copiadas" pelo Brasil para ajudar no combater à violência urbana. A matéria trouxe em tópicos ações que podem solucionar o problema da violência, apresentando resultados de pesquisas e dados estatísticos.

Outras quatro matérias, que juntas não ocuparam mais do que nove páginas, discutiram brevemente os problemas e investimentos em segurança pública, ações da Polícia Federal no combate ao crime e à violência gerada pelo terrorismo, de maneira clara e objetiva.

A Isto é, assim como a Veja, apresentou apenas cinco reportagens. Uma delas intitulada "Massacre no Rio - o que acontece no morro do Alemão" na edição n.1966, de 4 de julho, dividiu o destaque com a matéria de comportamento "Marginais da classe média" (p.68-72), que ganhou a capa da mesma edição com a manchete: "Ricos, intolerantes e criminosos", sobre o episódio dos jovens que espancaram uma doméstica no ponto de ônibus.

"O que leva jovens com família, dinheiro e acesso à boa educação a se comportarem como bárbaros sem motivo aparente?" (p. 70). A matéria trouxe exemplos de crimes cometidos por jovens de classe média e a opinião de especialistas sobre essas atitudes. Um texto crítico em que fica perceptível o trabalho de pesquisa realizado pelos repórteres.

Vale salientar que a Isto é foi a única revista, nesse período, que apresentou um editorial tratando a questão da violência, assinado pelo diretor editorial Carlos José Marques, sobre as expressivas ações de segurança pública planejadas para evitar quaisquer indícios de violência durante os Jogos PanAmericanos. Mesmo assim, pode-se perceber que a revista se pautou no corriqueiro, já divulgado pela imprensa. A análise mostrou que, quando se trata de violência, a abordagem muda pouco, mesmo em revistas diferentes. A fraca publicação de reportagens sobre o assunto, em termos quantitativos, também se deveu ao fato de, durante o período de análise, não ter ocorrido nenhum caso de violência grave, como chacinas, por exemplo. Em 2007, ano escolhido para a análise, alguns assuntos acerca da violência urbana tiveram maior destaque na mídia. Pode-se citar o assassinato do menino João Hélio, a violência desordenada no chamado Complexo do Alemão e a repercussão do filme Tropa de Elite.

O caso que obteve mais repercussão na mídia foi o de João Hélio, ocorrido no dia 7 de fevereiro de 2007. Embora a data não corresponda ao período de análise, revolveu-se dar atenção a esse evento pois, de certa forma, ele demonstrava o tipo característico de tratamento que a mídia dá a assuntos dramáticos que comovem a sociedade. O menino de apenas seis anos foi morto por assaltantes, após ter sido arrastado por muitos quilômetros pelas ruas do Rio de Janeiro, preso ao cinto de segurança do veículo roubado da família. Todos devem lembrar bem dessa cena, muito explorada pela mídia brasileira. O crime chocou o Brasil e gerou uma série de matérias sensacionalistas na imprensa nacional, além, é claro, de discussões acerca da maioridade penal no país.

\section{João Hélio}

Destaque para a cobertura das revistas Veja e Época. A primeira publicou matéria sobre o caso em duas edições (14 e 21 de fevereiro). Na edição do dia 14, o assunto foi capa tendo como manchete: "Arrastado por quatro bairros do Rio de Janeiro, morto, destroçado por bandidos e mais uma vez... NÃO VAMOS FAZER NADA?", acompanhada de uma foto do menino, com nome e idade.

A matéria de capa trazia o título "Sem limites para a barbárie" e o assunto ocupou seis páginas (4651) do periódico, com muitos apelos emocionais. Além das nove fotos que expunham a desgraça e o 
sofrimento daquela família, texto narrativo foi apresentado, um tanto quanto literário e bastante dramático. Trechos como "[...] começou, então, o pior drama que uma mãe pode viver - e uma trágica história que tirou a respiração de todos os brasileiros [...]”' (p.46), e "O que se passou depois foi uma cena difícil de imaginar, mesmo nos piores filmes de terror - aliás, nenhum roteirista ousou escrever uma cena daquela [...]” (p.47), demonstram o quão apelativo o texto é para chamar a atenção dos leitores.

Sensacionalismos à parte, a revista ganha pontos positivos quando publica na mesma edição, um texto crítico do jornalista Reinaldo Azevedo. Traz ainda um infográfico com o mapa e a rota que os traficantes seguiram arrastando o menino; e, principalmente, expõe a opinião de diversos especialistas sobre o que precisa e deve ser feito para diminuir a criminalidade no país.

$\mathrm{Na}$ edição de 21 de fevereiro, a Veja mudou o foco do acontecimento: "A falsa questão da pobreza" (p.46-47), quando discute o problema da maioridade penal e os motivos para a prática do crime por aqueles jovens. O box "O caminho do suplício" não deixa que o "sangue", como em todas matérias sobre violência, passe despercebido. Agora o trajeto do assassinato é descrito cuidadosamente, rua por rua, sem poupar detalhes.

A revista Época também publicou duas edições sobre o episódio, (dias 12 e 19 de fevereiro). A primeira delas, cinco dias após o crime, trazia " $\mathrm{O}$ HORROR, O HORROR: o crime bárbaro que chocou o país", e uma pequena foto de João Hélio na chamada de capa da revista. A matéria, que compreendia as páginas 86 a 90, repetia o título da chamada e acrescentava na linha de apoio: "Crime bárbaro em que criança é arrastada e morta no Rio de Janeiro reacende debate sobre a redução da maioridade penal".

O texto traz todos os acontecimentos do dia do crime de forma dramática, como é possível notar no trecho: "Na semana passada, a imagem de um corpo arrastado assombrou o Brasil, numa cena de horror que nem o mais imaginativo dos poetas conseguiria sonhar". No segundo parágrafo, outro trecho afirma a intenção apelativa da matéria: "Bestas. Monstros. Vermes. Feras. Assim reagiu, aos prantos e em choque, a sociedade, em cartas e e-mails enviados a jornais e revistas". As palavras fortes e a "generalização da dor" diante do caso é a forma utilizada para prender a atenção do leitor.

As seis fotos publicadas na matéria foram outra maneira de manter a "atração", no sentido sensacionalista da palavra. O carro com as marcas de sangue, o desenho feito por João Hélio, a imagem dos policiais agarrando pelo pescoço os presos enquanto eram detidos e o desespero da família durante o enterro do menino, garantiam o envolvimento emocional do leitor à matéria e o instigava a fazer a leitura completa dos textos.

$\mathrm{Na}$ terceira página, o tom era mais reflexivo e direcionava ao debate sobre a redução da maioridade penal, em uma abordagem positivamente diferenciada. Cita outros exemplos de crimes cometidos por menores, apresentam resultados de pesquisas feitas no mundo sobre o assunto e compara a legislação brasileira às de outros países. Além disso, apresenta um box: "Será que ele vence o crime?", discutindo as ações do então Secretário de Segurança Pública do Rio de Janeiro e expondo as medidas propostas por ele para combater a violência no estado. Um texto com informações concisas e que apresentava soluções concretas.

Na edição seguinte, de 19 de fevereiro, apareceram diversas reportagens (p.31-38) sobre o tema "Brasil, violência". O quadro "As propostas em discussão" apresentou a opinião de especialistas, assim como a entrevista "Cadeia não resolve", com um juiz da área criminal, na página 36. Mais duas reportagens, sobre outros dois casos, em que os presos eram menores, acrescentaram informações interessantes à edição.

A revista Isto é publicou apenas uma nota breve sobre o assunto, de caráter informativo, na edição de 14 de fevereiro, ocupando metade da página 20 , na seção "A semana". O acontecimento vinha com a cartola "barbárie" e o título: "Ladrões roubam carro e arrastam menino até a morte", acompanhado de duas fotos toleráveis, no sentido sensacionalista, e um texto de poucas linhas, expressamente narrativo sobre o caso.

O leitor da revista acabou sem as informações necessárias, pois a Isto é deixou a desejar. A revista apresentou apenas uma pequena nota sobre o crime e foi a única a abordar o assunto em editorial, que em 21 de fevereiro, trouxe a posição da revista sobre o 
caso, nas palavras de Carlos José Marques, diretor editorial, que discutiu mudanças a serem realizadas na lei, relativas à maioridade penal.

A Carta Capital causou surpresa. Mesmo em exemplares de meses posteriores ao do crime, não foi encontrada nenhuma matéria falando sobre o caso, ou seja, deixou de publicar um acontecimento de relevância social e perdeu a oportunidade de se manifestar e contribuir para uma discussão do problema da violência no país.

Apenas na edição de 21 de fevereiro, a coluna "Linha de Frente" (p.21), de Walter Fanganiello Maierovitch, publicou o texto "O crime compensa?", discutindo sobre a dificuldade de se alterar a lei, devido ao estatuto da criança e do adolescente. É um texto marcado por opinião, argumentando sobre a política criminal no Brasil. A nota propõe a redução de idade penal, a pena de morte ou medidas mais punitivas para criminosos.

\section{Considerações finais}

Quando o assunto é violência, violência urbana, as revistas são enfáticas. Elas não se limitam a informar. Tomam partido, julgam e condenam, especialmente quando se trata de crimes hediondos, como foi o caso de João Hélio. É nesses momentos que transparece mais claramente o viés sensacionalista das publicações. Geralmente, quanto mais grave é o fato, mais se explora a emoção humana. Percebeu-se na análise que as revistas Veja e Época foram as que mais exploraram esse aspecto. A opção pela linguagem sensacionalista, nesses episódios, com a narração dramática dos fatos (ilustradas por fotos chocantes), parece mobilizar boa parte dos veículos de comunicação. Nesses momentos as revistas nacionais expõem suas caras, seus "compromissos", ou melhor, a falta de compromisso com a informação. E o caso João Hélio serviu de forma exemplar para caracterizar o tipo de tratamento dado pelas revistas nacionais à violência. Resolveu-se investigar esse caso como forma de complementar a análise desenvolvida de julho a setembro de 2007, período atípico de violência no país. Foram analisadas 12 edições das quatro principais revistas brasileiras, em um período considerado pelos pesquisadores como de "normalidade", sem ocorrência de crimes hediondos.

Esperava-se um tratamento intensivo do tema violência urbana, mas isso acabou não ocorrendo por conta de dois acontecimentos importantes que atraíram a atenção dos periódicos: a nova crise política do Governo Lula, com a história do Mensalão, e os Jogos Pan-Americanos. Contudo, mesmo neste período, foi possível fazer algumas inferências importantes sobre a abordagem do assunto nas revistas Veja, Isto é, Carta Capital e Época. Quem mais investiu no tema violência foram a Carta Capital, duas capas e catorze matérias, e a revista Época, com duas capas e dez matérias, seguidas pela Isto é e a Veja, fato que pode foi verificado na análise.

Apesar da pouca exploração do assunto, foi possível observar que mesmo nesse período os veículos investigados utilizaram-se da linguagem sensacionalista - textos dramáticos, fotos e declarações chocantes. Esses são os elementos mais marcantes na abordagem da violência urbana e isso acaba assumindo uma função primordial quando a reportagem trata de fatos graves, que abalam a rotina de uma cidade e do país.

Os meios de comunicação, ao explorarem o assunto desta forma, acabam contribuindo para aprofundar o temor e a ignorância do público, quando deveria informar, usando mensagens de forma errada ou profundamente estereotipadas (MELLO, 1999, p. 138). Não é o caso, entretanto, de culpar a mídia como a única responsável pela dramatização da violência, na medida em que ela apenas reforça certas concepções presentes na sociedade.

É essencial que seja resgatado o caráter ético dos veículos de comunicação, também responsáveis por proporcionar à população em geral, melhores condições de vida por meio da informação. Exigir que - para além da simples informação, críticas e posicionamentos sensacionalistas - os meios de comunicação tragam sugestões e ideias capazes de promover mudanças e melhorias no contexto social atual. Algumas das revistas analisadas chegaram a fazer ensaios neste sentido, colocando em pauta o assunto e trazendo a contribuição de especialistas, com vistas à formulação de políticas e ações de combate à criminalidade. Esta preocupação foi apresentada, com 
mais ênfase, pela revista Carta Capital. A publicação apresentou uma série de reportagens discutindo o problema da segurança no país e diversos pontos de vista de especialistas, que indicaram sugestões e ideias com a finalidade de reduzir a violência urbana. A revista Época também tomou partido, chamando a atenção para investimentos no setor de segurança. A respeito da matéria sobre o tráfico no Complexo do Alemão, a publicação, com a ajuda de especialistas, propôs oito sugestões para melhorar a segurança das cidades brasileiras.

Das quatro revistas, a que trouxe menos reportagens sobre a violência urbana, foi a Veja, que no período da análise estava mais preocupada com os bastidores da política. Ela esbanjou editorias e matérias especiais sobre política, fato esperado diante da sua linha editorial, que prioriza a temática e os grandes escândalos políticos. Além disso, no período da análise estava em pauta o escândalo do Mensalão. Assim como a Veja, a revista Isto é também expôs pouco o assunto violência urbana, enfatizando a guerra do tráfico no Complexo do Alemão.

Convém salientar que os meios de comunicação têm um papel fundamental a desenvolver junto da sociedade. Para isso, é necessário investir mais em informação e menos em sensacionalismo; é necessário proporcionar reflexões permanentes e novas proposições à solução dos problemas brasileiros, especialmente quando se trata da violência nas cidades.

\section{REFERÊNCIAS}

ARENDT, H. Sobre a violência. 3. ed. Rio de Janeiro: Relume Dumara, 2001.

BARDIN, L. Análise de conteúdo. Lisboa: Edições 70, 2000.

DIAS, A. R. F. O jornalismo. In: O discurso da violência. 2 ed. São Paulo: Cortez, 2003.

MAFFESOLI, M. Dinâmica da violência. São Paulo: Revista dos Tribunais, 1987.

MELLO, S. L. A violência urbana e a exclusão dos jovens. In: _. As artimanhas da exclusão. Rio de Janeiro: Petrópolis, 1999.

MICHAUD, Y. A violência. São Paulo: Ática, 1989.

. Violence at politique. Col. 'Les Essais'. Paris: Gallimard, 1978.

MORAIS, R. O que é violência urbana. 6. ed. São Paulo: Brasiliense, 1985.

ODALIA, N. O que é violência. 6. ed. São Paulo: Brasiliense, 1991.

PIRES, C. A violência no Brasil. 10. ed. São Paulo: Ed. Moderna, 1994.

PINHEIRO, P. S. Crime, violência e poder. São Paulo: Brasiliense, 1983.

WAINBERG, J. A. Mídia e terror: comunicação e violência política. São Paulo: Paulus, 2005.

Recebido em novembro de 2013. Aceito em março de 2014. 